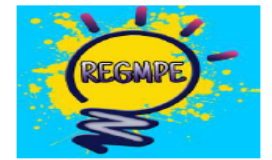

\title{
Práticas de Gestão do Conhecimento aplicadas no sistema de EaD de uma instituição federal de ensino no Sul Fluminense
}

\section{Knowledge Management practices applied in the Distance Education system of a federal educational institution in the southern region of Rio de Janeiro}

\section{RESUMO}

Atualmente, organizações públicas e privadas reconhecem a importância e aplicam a Gestão do Conhecimento (GC) como ferramenta de gestão para melhorarem seu desempenho e eficiência e obterem de vantagens competitivas. No segmento da EaD (educação a distância), o crescimento da modalidade faz com que muitas organizações de ensino busquem se posicionar no mercado e, com isso, utilizem práticas de GC para se atualizarem e se manterem competitivas e inovadoras, a partir da diferenciação pela forma como aplicam este conhecimento. Nesse sentido, o presente artigo teve como objetivo diagnosticar as práticas de GC aplicadas no sistema de educação a distância de uma instituição federal de ensino na região sul do estado do Rio de Janeiro (Sul Fluminense). A pesquisa caracteriza-se como qualitativa/quantitativa, exploratório-descritiva, por meio de um estudo de caso. A coleta dos dados foi realizada por meio da observação participante e da aplicação de um questionário semiestruturado aos integrantes desse sistema, para identificar e verificar a utilização dessas práticas no cotidiano da EaD. Os resultados mostraram que poucas práticas de GC são aplicadas, o que indica que a instituição pode explorar outras práticas de $\mathrm{GC}$ na $\mathrm{EaD}$, com o intuito de aplicá-las no segmento e, assim, qualificar o ensino nessa modalidade e garantir sua competitividade neste mercado. Para tanto, foram propostas recomendações para uma implementação efetiva da GC no sistema de EaD da instituição pesquisada.

Palavras-chave: Gestão do Conhecimento; Práticas de Gestão do Conhecimento; Educação a Distância.

\footnotetext{
ABSTRACT

Currently, public and private organizations recognize the importance and appling Knowledge Management (KM) as a management tool to improve their performance and efficiency and obtain competitive advantages. In the distance education (DE) segment, the growth of the modality causes many teaching organizations to seek to position themselves in the market and,

${ }^{1}$ E-mail: thiagovrd@ gmail.com; Mestre em Gestão e Estratégia pela Universidade Federal Rural do Rio de Janeiro (UFRRJ) e Analista de Tecnologia da Informação no Instituto Federal do Rio de Janeiro (IFRJ); ORCID: https://orcid.org/0000-0002-1682-6160

${ }^{2}$ E-mail: andre.cribb@embrapa.br; Pesquisador da Embrapa Agroindústria de Alimentos e Professor do Programa de Pós-Graduação em Gestão e Estratégia da Universidade Federal Rural do Rio de Janeiro (UFRRJ); ORCID: http://orcid.org/0000-0003-4243-394X

Calmeto, T.L.L., Cribb, A.Y.; Práticas de Gestão do Conhecimento aplicadas no sistema de EaD de uma instituição federal de ensino no Sul Fluminense. Revista de Empreendedorismo e Gestão de Micro e Pequenas Empresas V.5, N³3, p.192-212, Set/Dez. 2020. Artigo recebido em 15/11/2020. Última versão recebida em 18/12/2020. Aprovado em 28/12/2020.
} 


\section{Práticas de Gestão do Conhecimento aplicadas no sistema de EaD de uma instituição federal de ensino no Sul Fluminense}

with this, use KM practices to update themselves and remain competitive and innovative, based on the differentiation by how they apply this knowledge. In this sense, the present article aimed to diagnose the KM practices applied in the distance education system of a federal educational institution in the southern region of the state of Rio de Janeiro (known as Southern Fluminense). The research is characterized as qualitative/quantitative, exploratory-descriptive, through a case study. The data collection was carried out through participant observation and the application of a semi-structured questionnaire to the members of this system, to identify and verify the use of these practices in the daily distance education The results showed us that few KM practices are applied, which indicates that the institution can explore other KM practices in distance education, in order to apply them in the segment and, thus, qualify teaching in this modality and guarantee its competitiveness in this area. Therefore, recommendations were proposed for an effective implementation of KM in the DE system of the researched institution.

Keywords: Knowledge Management; Knowledge Management Practices; Distance Education.

\section{INTRODUÇÃO}

As organizações do mundo atual passam por transformações a todo tempo, para adequar seus processos de negócio a novas tendências, obter melhorias em seus produtos e serviços, e garantir a satisfação de seus usuários e clientes, como forma de garantir sua sobrevivência e perenidade, em um ambiente marcado pela alta competitividade.

Diante desse cenário, a importância de gerir o conhecimento faz com que as organizações se atentem para a administração do conhecimento de forma estratégica, de modo que este conhecimento venha oferecer a elas vantagens competitivas (Cribb, 2010; Nonaka \& Takeuchi, 2008).

Nesse contexto, surge a Gestão do Conhecimento (GC), que consiste numa coleção de processos que possibilita e rege a criação, armazenamento, disseminação e utilização de conhecimentos, visando a melhoria do desempenho organizacional; sendo, portanto, uma aliada em termos de diferencial competitivo e das estratégias organizacionais (Davenport \& Prusak, 2012; Silva \& Burger, 2018).

A GC se caracteriza por ser uma ferramenta de gestão que estimula e impulsiona e a capacidade de aprendizagem e inovação em processos, produtos e serviços tanto em organizações privadas (que visam competitividade, lucro, crescimento e sobrevivência) quanto públicas (que focam eficiência, desempenho e efetividade na prestação de serviços públicos) (Batista, 2012; Bento et al., 2017).

Nas instituições de ensino, sejam públicas ou privadas, onde o conhecimento é o negócio e finalidade (Brito \& Bolson, 2014), geri-lo com atenção é essencial, como forma de garantir a continuidade do conhecimento organizacional, com ações e práticas que promovam a preservação, revisão, busca e atualização desse conhecimento. 


\section{Práticas de Gestão do Conhecimento aplicadas no sistema de EaD de uma instituição federal de ensino no Sul Fluminense}

Nesse sentido, a EaD (educação a distância), modalidade de ensino que cresceu no Brasil nos últimos anos, requer a utilização de conhecimentos específicos, que devem ser atualizados e geridos adequadamente por estas instituições, pela aplicação de práticas de GC, para refletir na qualidade no ensino e na melhoria dos processos educacionais e organizacionais, de modo a se tornarem mais competitivas (Brasil, 2019; Cruz \& Molina, 2019).

A principal estratégia das instituições de $\mathrm{EaD}$ é a atualização sistemática desses conhecimentos, para promover mudanças e inovação no contexto educacional e organizacional, uma vez que a atuação e gestão na modalidade está associada à gestão de conhecimentos individuais e organizacionais (Alarcon \& Spanhol, 2015; Cruz \& Molina, 2019; Hack, 2011).

No entanto, nem sempre os conhecimentos aplicáveis à EaD são geridos de modo que permitam ser compartilhados, retidos e aproveitados nessas instituições, por conta da dinâmica dos processos que envolvem o trabalho na $\mathrm{EaD}$, das mudanças e da rotatividade de pessoas, o que pode levar à perda de conhecimentos relevantes (Alarcon \& Spanhol, 2015; Cruz \& Molina, 2019). E no universo da presente pesquisa não é diferente.

Diante do exposto, o presente estudo tem como foco a preocupação com a construção, retenção, atualização e a continuidade do conhecimento aplicável à modalidade $\mathrm{EaD}$ no sistema de EaD de uma instituição federal de ensino no Sul Fluminense.

Neste sentido, o objetivo do estudo foi diagnosticar as práticas de Gestão do Conhecimento aplicadas no universo acima citado. Para tanto, foi aplicado um questionário aos integrantes deste universo, para identificar o uso dessas práticas no cotidiano da $\mathrm{EaD}$, além da observação de como tais práticas são aplicadas no ambiente organizacional. A partir desse diagnóstico, foi possível avaliar como a gestão do conhecimento vem sendo praticada e contribuir com recomendações para uma GC mais efetiva.

Além da introdução, o artigo se subdivide em mais quatro seções. A segunda seção discute sobre a GC nas organizações, as práticas de GC e sobre o contexto da EaD. A terceira seção fala sobre a metodologia. A quarta seção apresenta os resultados e discussões. Por fim, a quinta seção apresenta as considerações finais.

\section{REFERENCIAL TEÓRICO}

\subsection{GESTÃO DO CONHECIMENTO}

A Sociedade da Informação e do Conhecimento se caracteriza pelo dinamismo e excesso de informações. Nesse contexto, informação e conhecimento são fundamentais para o desenvolvimento de uma sociedade (Alarcon \& Spanhol, 2015; Drucker, 1999). 


\section{Práticas de Gestão do Conhecimento aplicadas no sistema de EaD de uma instituição federal de ensino no Sul Fluminense}

O conhecimento se tornou o maior diferencial competitivo das organizações modernas; um ativo que impulsiona o seu desenvolvimento e gera inovação, pela criação ou aquisição de conhecimentos, com vistas à manutenção da competitividade, inovação e sobrevivência neste ambiente dinâmico e de mudanças rápidas (Cribb, 2010; Davenport \& Prusak, 2012; Nonaka \& Takeuchi, 2008; Santos et al., 2019; Schreiber, 2015).

Dessa forma, diversas organizações buscam na Gestão do Conhecimento o diferencial para qualificar processos e serviços, sendo o conhecimento decisivo para alcançar objetivos estratégicos, implementar novas práticas de gestão, melhorar desempenho, bons resultados e vantagem competitiva (Alarcon \& Spanhol, 2015; Batista, 2012).

A Gestão do Conhecimento (GC) consiste na criação de valor a partir de bens intangíveis da organização, dando ao conhecimento "status" de ativo intangível. Deixou de ser "modismo" e passou a fazer parte da estratégia das organizações (Sveiby, 1998).

Nonaka e Takeuchi (2008) definem a GC como um processo pelo qual as organizações buscam novas formas de criar e expandir conhecimento. Trata-se da criação contínua de novos conhecimentos, compartilhando-os pela organização e incorporando-os em novos produtos, serviços e tecnologias, e que acarretam em mudança no ambiente organizacional.

Para que o conhecimento proporcione vantagens organizacionais, reconhece-se que o conhecimento tácito das pessoas é a base do conhecimento de uma organização, e que estas devem dispor de ambientes propícios para a interação entre elas, de modo a tornar este conhecimento explícito e disseminado, formando um conjunto de conhecimentos que, se bem geridos, podem trazer diversas melhorias (Cribb, 2010; Nonaka \& Takeuchi, 2008).

Com o entendimento de que o conhecimento é um ativo estratégico e intangível, a GC nas organizações incentiva construir relacionamentos entre seus membros, para que novos conhecimentos sejam gerados e compartilhados e, assim, elas criem diferenciais para obter vantagem competitiva e melhoria contínua (Santos et al., 2019).

Portanto, a GC é a capacidade que permite às organizações se desenvolverem, inovarem e reforçarem a sua competitividade; uma forma estruturada de tratar o conhecimento, por meio da utilização de práticas que impulsionam a criação, retenção, compartilhamento e aplicação do conhecimento (Batista, 2012; Jannuzzi, Falsarella \& Sugahara, 2016; Schreiber, 2015).

\subsection{PRÁTICAS DE GESTÃO DO CONHECIMENTO}

As iniciativas de GC nas organizações devem observar a busca de processos e tecnologias adequadas, e considerar a influência cultural e comportamental das pessoas, para 


\section{Práticas de Gestão do Conhecimento aplicadas no sistema de EaD de uma instituição federal de ensino no Sul Fluminense}

terem sucesso. Sendo assim, os pilares da GC nas organizações são: pessoas, processos e tecnologia (Neves et al., 2018).

A efetividade da GC decorre da interação entre pessoas e tecnologia e, conjuntamente com os processos desenvolvidos, dão o suporte para a GC, com práticas e ações que visem reter, compartilhar e aplicar o conhecimento nas organizações (Batista, 2012; Bento et al., 2017).

Esse conjunto de práticas e ações de gestão organizacional pode ser categorizado de acordo com cada um dos pilares da GC acima descritos (Batista, 2012; Neves et al., 2018), conforme pode ser visto no quadro a seguir (Quadro 1).

Quadro 1

Categorias de práticas da GC

\begin{tabular}{|c|c|}
\hline Categorias de práticas de GC & Definição \\
\hline $\begin{array}{c}\text { Práticas e ações com foco em } \\
\text { pessoas }\end{array}$ & $\begin{array}{c}\text { Facilitam o compartilhamento e transferência de } \\
\text { informações e conhecimentos. }\end{array}$ \\
\hline $\begin{array}{c}\text { Práticas e ações voltadas a } \\
\text { estruturação de processos } \\
\text { organizacionais }\end{array}$ & $\begin{array}{c}\text { Facilitam a geração, retenção, organização e } \\
\text { disseminação do conhecimento organizacional. }\end{array}$ \\
\hline $\begin{array}{c}\text { Práticas e ferramentas com foco } \\
\text { na base funcional e tecnológica }\end{array}$ & $\begin{array}{c}\text { Dão suporte à GC (automação da gestão das } \\
\text { informações, dos sistemas e das ferramentas de TI para } \\
\text { obtenção, difusão e colaboração). }\end{array}$ \\
\hline
\end{tabular}

Fonte: Adaptado de Batista (2012).

Cada um dos pilares da GC possui práticas associadas, que podem ser incorporadas pelas organizações, e que tem o propósito de estimular a dinâmica do conhecimento (Batista, 2012; Batista \& Quandt, 2015; Hellmann, 2007; Leuch, 2006). Assim, as organizações podem aplicar práticas de GC de maneira combinada entre as categorias de práticas.

A literatura apresenta inúmeras práticas de GC, conforme a relação de cada uma delas com os pilares da GC. Porém, ressalta que algumas abrangem todos eles, por influenciar em aspectos comportamentais e mudanças em processos organizacionais (Batista (2012), Batista \& Quandt (2015), Hellmann (2007), Leuch (2006)). Tais práticas de GC podem ser vistas no quadro abaixo (Quadro 2), junto com sua descrição.

Quadro 2

Práticas de Gestão do Conhecimento - Descrição

\begin{tabular}{|c|c|l|}
\hline $\mathbf{N}^{\mathbf{0}}$ & Prática de GC & \multicolumn{1}{|c|}{ Descrição da prática } \\
\hline 1 & $\begin{array}{c}\text { Fóruns } \\
\text { presenciais e }\end{array}$ & $\begin{array}{l}\text { Espaços para discutir, homogeneizar e compartilhar informações, } \\
\text { ideias e experiências que contribuirão para desenvolver } \\
\text { competências e aperfeiçoar processos e atividades da organização. }\end{array}$ \\
\hline
\end{tabular}

REGMPE, Brasil-BR, V.5, No3, p. 192-212, Set./Dez.2020 www.revistas.editoraenterprising.net Página 196 


\begin{tabular}{|c|c|c|}
\hline & $\begin{array}{l}\text { virtuais e listas } \\
\text { de discussão }\end{array}$ & \\
\hline 2 & $\begin{array}{l}\text { Comunidades de } \\
\text { prática }\end{array}$ & $\begin{array}{l}\text { São grupos informais e interdisciplinares de pessoas unidas em } \\
\text { torno de um interesse comum. São organizadas de modo a permitir } \\
\text { a colaboração de pessoas internas ou externas ao grupo; propiciam } \\
\text { a transferência de melhores práticas e o acesso a especialistas, bem } \\
\text { como a reutilização de modelos, conhecimentos e lições aprendidas. }\end{array}$ \\
\hline 3 & Narrativas & $\begin{array}{l}\text { Técnicas utilizadas em ambientes de GC para descrever assuntos } \\
\text { complicados, expor situações, comunicar lições aprendidas, ou } \\
\text { interpretar mudanças culturais. São relatos retrospectivos de pessoal } \\
\text { envolvido nos eventos ocorridos. }\end{array}$ \\
\hline 4 & Mentoring & $\begin{array}{l}\text { Modalidade de gestão do desempenho na qual um mentor modela } \\
\text { as competências de um indivíduo ou grupo, observa e analisa o } \\
\text { desempenho, e retroalimenta a execução das atividades. }\end{array}$ \\
\hline 5 & Coaching & $\begin{array}{l}\text { Similar ao anterior, mas o coach não participa das atividades. } \\
\text { Orienta, dialoga e acompanha, alinhado às diretrizes estratégicas. }\end{array}$ \\
\hline 6 & $\begin{array}{l}\text { Aprendizagem } \\
\text { Organizacional }\end{array}$ & $\begin{array}{l}\text { Consiste em mudanças na base de conhecimentos da organização, } \\
\text { na criação de estruturas coletivas de referência e no crescimento da } \\
\text { competência organizacional para agir e resolver problemas. }\end{array}$ \\
\hline 7 & $\begin{array}{l}\text { Educação } \\
\text { corporativa }\end{array}$ & $\begin{array}{l}\text { Oferecer processos de educação continuada para atualização de } \\
\text { funcionários. Pode ser implementada sob a forma de universidade } \\
\text { corporativa, sistemas de ensino a distância, etc. }\end{array}$ \\
\hline 8 & Brainstorming & $\begin{array}{l}\text { Atividade que reúne grupos de pessoas para gerar ideias inovadoras. } \\
\text { O processo é dividido em } 2 \text { etapas: divergente e convergente. Na } \\
\text { primeira etapa não há julgamentos sobre as ideias; e na segunda } \\
\text { etapa as mesmas ideias são analisadas com critérios de viabilidade. }\end{array}$ \\
\hline 9 & $\begin{array}{l}\text { Assistência de } \\
\text { colegas }\end{array}$ & $\begin{array}{l}\text { Técnica usada por um grupo de projetos que solicita assistência à } \\
\text { colegas, externos ou internos ao grupo, para resolver algum } \\
\text { problema que o grupo esteja enfrentando. É uma consultoria } \\
\text { informal, realizada por colegas de trabalho do mesmo grupo ou de } \\
\text { outros, para resolver um problema pontual. }\end{array}$ \\
\hline 10 & Socialização & $\begin{array}{l}\text { Iniciativas que favorecem a socialização entre os indivíduos e a } \\
\text { conversão de conhecimento "tácito-tácito". }\end{array}$ \\
\hline 11 & Reuniões & $\begin{array}{l}\text { São encontros periódicos onde são discutidos temas de trabalho, } \\
\text { administrativos, resultados de pesquisas, etc. }\end{array}$ \\
\hline 12 & $\begin{array}{l}\text { Revisão de } \\
\text { aprendizagem }\end{array}$ & $\begin{array}{l}\text { Técnica que promove a aprendizagem individual e coletiva durante } \\
\text { o processo de trabalho. Normalmente é conduzida após reuniões, } \\
\text { projetos ou eventos. }\end{array}$ \\
\hline 13 & $\begin{array}{l}\text { Revisão pós- } \\
\text { ação }\end{array}$ & $\begin{array}{l}\text { Técnica para avaliar e capturar as lições aprendidas após o término } \\
\text { de algum projeto. Permite aos membros do grupo saberem o que } \\
\text { aconteceu, o porquê aconteceu e como manter os pontos fortes e } \\
\text { melhorar os pontos fracos. }\end{array}$ \\
\hline 14 & $\begin{array}{l}\text { Espaço físico } \\
\text { colaborativo }\end{array}$ & $\begin{array}{l}\text { Espaço físico que possibilita interações entre membros do grupo e } \\
\text { proporciona um ambiente de trabalho favorável ao } \\
\text { compartilhamento e a criação de conhecimento. }\end{array}$ \\
\hline 15 & $\begin{array}{l}\text { Espaço virtual } \\
\text { colaborativo }\end{array}$ & $\begin{array}{l}\text { Espaço virtual que possibilita que pessoas trabalhem juntas, } \\
\text { independentemente de onde estejam localizados. Envolve a }\end{array}$ \\
\hline
\end{tabular}

REGMPE, Brasil-BR, V.5, N³, p. 192-212, Set./Dez.2020 www.revistas.editoraenterprising.net Página 197 

federal de ensino no Sul Fluminense

\begin{tabular}{|c|c|c|}
\hline & & $\begin{array}{l}\text { combinação de ferramentas de compartilhamento de documentos, } \\
\text { videoconferência, etc. }\end{array}$ \\
\hline 16 & $\begin{array}{l}\text { Compartilhamen } \\
\text { to de vídeos }\end{array}$ & $\begin{array}{l}\text { Habilidade de publicar conteúdos em vídeo na web, mesmo que } \\
\text { apenas para um público específico ou então para o mundo inteiro. }\end{array}$ \\
\hline 17 & $\begin{array}{l}\text { Melhores } \\
\text { práticas }\end{array}$ & $\begin{array}{l}\text { Registrar os pontos positivos e negativos de determinado } \\
\text { procedimento ou processo e reutilizá-los, quando necessário. São } \\
\text { definidas como um procedimento validado para realizar uma tarefa } \\
\text { ou solucionar um problema. Inclui o contexto no qual pode ser } \\
\text { aplicada. Documentadas em bases de dados, manuais ou diretrizes. }\end{array}$ \\
\hline 18 & Benchmarking & $\begin{array}{l}\text { Busca sistemática das melhores referências para comparar } \\
\text { processos, produtos e serviços interna e externamente. }\end{array}$ \\
\hline 19 & $\begin{array}{l}\text { Normalização e } \\
\text { padronização }\end{array}$ & $\begin{array}{l}\text { Elaborar e estabelecer normas, padrões, procedimentos e } \\
\text { regulamentos que caracterizam uma organização. }\end{array}$ \\
\hline 20 & $\begin{array}{l}\text { Mapeamento de } \\
\text { processos }\end{array}$ & $\begin{array}{l}\text { Analisar os processos organizacionais para promover ou melhorar } \\
\text { processos existentes ou de implantar uma nova estrutura, voltada } \\
\text { para processos na empresa. }\end{array}$ \\
\hline 21 & $\begin{array}{l}\text { Mapeamento do } \\
\text { conhecimento }\end{array}$ & $\begin{array}{l}\text { Localizar conhecimentos importantes sobre processos, produtos, } \\
\text { serviços e relacionamentos com os clientes, dentro das empresas e } \\
\text { depois, publicar e divulgar onde encontrá-los. }\end{array}$ \\
\hline 22 & $\begin{array}{l}\text { Inteligência } \\
\text { competitiva }\end{array}$ & $\begin{array}{l}\text { Transformação de dados em inteligência, com o objetivo de apoiar } \\
\text { a tomada de decisão. Visam extrair inteligência de informações, por } \\
\text { meio da captura e conversão das informações em diversos formatos, } \\
\text { e extrair conhecimento a partir das informações. O conhecimento } \\
\text { obtido de fontes internas ou externas, formais ou informais, é } \\
\text { formalizado, documentado e armazenado para facilitar o seu acesso. }\end{array}$ \\
\hline 23 & $\begin{array}{l}\text { Sistema de } \\
\text { gestão por } \\
\text { competências }\end{array}$ & $\begin{array}{l}\text { Mapear os processos-chave, as competências essenciais associadas } \\
\text { a estes, as atribuições, as atividades e habilidades existentes e } \\
\text { necessárias e os registros para superar deficiências. }\end{array}$ \\
\hline 24 & $\begin{array}{l}\text { Memória } \\
\text { organizacional / } \\
\text { lições } \\
\text { aprendidas }\end{array}$ & $\begin{array}{l}\text { Registro do conhecimento organizacional sobre processos, } \\
\text { produtos, serviços e relacionamentos com os clientes. As lições } \\
\text { aprendidas são relatos de experiências onde se registra o que } \\
\text { aconteceu, as expectativas criadas e o que restou de aprendizado. } \\
\text { Criar e manter um sistema de conhecimentos e habilidades que } \\
\text { preserva e armazena percepções e experiências, para que possam } \\
\text { ser recuperadas e utilizadas posteriormente. }\end{array}$ \\
\hline 25 & $\begin{array}{l}\text { Banco de } \\
\text { competências } \\
\text { individuais }\end{array}$ & $\begin{array}{l}\text { Repositório de informações sobre a capacidade técnica, científica, } \\
\text { artística e cultural das pessoas. Contém perfil, experiência, área de } \\
\text { atuação e especialidades, competências, etc. }\end{array}$ \\
\hline 26 & $\begin{array}{c}\text { Banco de } \\
\text { competências } \\
\text { organizacionais }\end{array}$ & $\begin{array}{l}\text { Repositório de informações sobre a localização de conhecimento na } \\
\text { organização, com fontes de consulta e pessoas ou equipes } \\
\text { detentoras de determinado conhecimento. }\end{array}$ \\
\hline 27 & Taxonomia & $\begin{array}{l}\text { Técnica que possibilita estruturar e organizar informações, } \\
\text { documentos, bibliotecas virtuais e temáticas de pesquisa e em geral. }\end{array}$ \\
\hline 28 & $\begin{array}{l}\text { Bases de } \\
\text { conhecimento }\end{array}$ & $\begin{array}{l}\text { São bases de dados ou conhecimento acumulados sobre um } \\
\text { determinado assunto. São estruturadas para explicitação de } \\
\text { conhecimentos, pela construção colaborativa do conhecimento por } \\
\text { membros do grupo. As bases de conhecimento são úteis para manter } \\
\text { conhecimentos explícitos críticos para um grupo (ou organização). }\end{array}$ \\
\hline
\end{tabular}

REGMPE, Brasil-BR, V.5, No3, p. 192-212, Set./Dez.2020 www.revistas.editoraenterprising.net Página 198 

federal de ensino no Sul Fluminense

\begin{tabular}{|c|c|c|}
\hline 29 & $\begin{array}{l}\text { Repositórios de } \\
\text { conhecimento }\end{array}$ & $\begin{array}{l}\text { É a externalização do conhecimento considerado "crítico", devido } \\
\text { a seu impacto no desempenho organizacional. Os repositórios do } \\
\text { conhecimento servem para preservar, gerenciar e alavancar a } \\
\text { memória organizacional. }\end{array}$ \\
\hline 30 & $\begin{array}{l}\text { Gestão do } \\
\text { capital } \\
\text { intelectual }\end{array}$ & $\begin{array}{l}\text { Recursos disponíveis no ambiente institucional, de difícil } \\
\text { qualificação e mensuração, mas que contribuem para os seus } \\
\text { processos produtivos e sociais. Inclui mapeamento e gestão dos } \\
\text { ativos do conhecimento. }\end{array}$ \\
\hline 31 & $\begin{array}{l}\text { Ferramentas de } \\
\text { colaboração }\end{array}$ & $\begin{array}{l}\text { Sistemas informatizados que capturam e difundem conhecimento e } \\
\text { experiência entre trabalhadores e setores. Podem constituir-se em } \\
\text { repositórios de conhecimento para a organização, propiciando } \\
\text { acesso a todas as informações e aplicações, e também como } \\
\text { plataforma para comunidades de prática, melhores práticas, etc. }\end{array}$ \\
\hline 32 & Voz sobre IP & $\begin{array}{l}\text { Transmissão de áudio e vídeo entre computadores, com conexão de } \\
\text { alta velocidade e outros equipamentos (câmera, fones, etc.). }\end{array}$ \\
\hline 33 & $\begin{array}{l}\text { Redes sociais e } \\
\text { E-mails }\end{array}$ & $\begin{array}{l}\text { Grupo de pessoas que compartilham uma área comum de interesse. } \\
\text { Servem de suporte para interagir socialmente na Internet. Permite } \\
\text { encontrar pessoas, compartilhar conteúdo, facilitar a comunicação, } \\
\text { etc. E-mail é uma forma de correio eletrônico, para comunicação. }\end{array}$ \\
\hline 34 & $\begin{array}{l}\text { Ferramentas de } \\
\text { busca avançada }\end{array}$ & $\begin{array}{l}\text { Mecanismo que ao ser compreendido melhora a qualidade de } \\
\text { buscas sobre determinado conteúdo na Internet ou portais internos. }\end{array}$ \\
\hline 35 & $\begin{array}{l}\text { Sistemas de } \\
\text { workflow }\end{array}$ & $\begin{array}{l}\text { Utilizar ferramentas de automação do fluxo de documentos e } \\
\text { processos voltados ao controle da qualidade da informação. }\end{array}$ \\
\hline 36 & $\begin{array}{l}\text { Gestão de } \\
\text { conteúdo }\end{array}$ & $\begin{array}{l}\text { Trata da representação dos processos de seleção, captura, } \\
\text { classificação, indexação, registro e depuração de informações. }\end{array}$ \\
\hline 37 & $\begin{array}{l}\text { Gestão } \\
\text { eletrônica de } \\
\text { documentos } \\
\text { (GED) }\end{array}$ & $\begin{array}{l}\text { Sistemas informatizados de controle de emissão, edição e } \\
\text { acompanhamento da tramitação, distribuição, arquivamento e } \\
\text { descarte de documentos. }\end{array}$ \\
\hline 38 & Data Warehouse & $\begin{array}{l}\text { Tecnologia de rastreamento de dados com arquitetura hierarquizada } \\
\text { disposta em bases relacionais, permitindo versatilidade na } \\
\text { manipulação de grandes massas de dados. }\end{array}$ \\
\hline 39 & Data Mining & $\begin{array}{l}\text { Mineradores de dados são instrumentos com alta capacidade de } \\
\text { associação de termos, permitindo-lhes "garimpar" assuntos ou } \\
\text { temas específicos. }\end{array}$ \\
\hline 40 & $\begin{array}{l}\text { BSC (Balanced } \\
\text { ScoreCard) }\end{array}$ & $\begin{array}{l}\text { Modelo de gestão estratégica que procura estabelecer quais os } \\
\text { indicadores de desempenho mais importantes, como esses } \\
\text { indicadores qualitativos ou quantitativos se relacionam entre si e } \\
\text { quais geram valor a longo prazo. }\end{array}$ \\
\hline 41 & $\begin{array}{l}\text { ERP (Enterprise } \\
\text { Resource } \\
\text { Planning) }\end{array}$ & $\begin{array}{l}\text { São sistemas que integram todos os dados e processos de uma } \\
\text { organização em um único sistema. É uma plataforma que integra } \\
\text { diversos departamentos de uma organização, e possibilita } \\
\text { automatizar e armazenar as informações negociais. }\end{array}$ \\
\hline 42 & $\begin{array}{l}\text { DSS (Decision } \\
\text { Support System) }\end{array}$ & $\begin{array}{l}\text { Sistema de informação especialmente desenvolvido para apoiar a } \\
\text { solução de problemas não estruturados, aperfeiçoando a tomada de } \\
\text { decisão. Usa dados, tem interface amigável e permite a quem for } \\
\text { tomar decisões ter suas próprias percepções. }\end{array}$ \\
\hline
\end{tabular}

Fonte: Adaptado de Batista (2012), Batista \& Quandt (2015), Hellmann (2007) e Leuch (2006).

REGMPE, Brasil-BR, V.5, N³, p. 192-212, Set./Dez.2020 www.revistas.editoraenterprising.net Página 199 


\section{Práticas de Gestão do Conhecimento aplicadas no sistema de EaD de uma instituição federal de ensino no Sul Fluminense}

Tais práticas ajudam os membros de uma organização a aprender e disseminar conhecimentos para melhorar a qualidade do trabalho, reduzir custos e riscos, e auxiliar decisões. Assim, diversas organizações concentram esforços e investimentos em desenvolver ações e práticas de GC para aumentar a competitividade (Bento et al., 2017).

Portanto, a GC se faz com a aplicação dessas práticas, e devem ser trabalhadas de modo que o conhecimento seja compartilhado e utilizado em favor da organização, e proporcione inovação, valor, resultados e diferencial competitivo (Batista, 2012; Silva \& Burger, 2018).

\subsection{EDUCAÇÃO A DISTÂNCIA (EaD) E A GC NA EaD}

A educação a distância (EaD) é uma modalidade de ensino que se baseia na construção do conhecimento, pela utilização de recursos tecnológicos para estudos, onde a comunicação é feita por meio de linguagem própria para a interação na $\mathrm{EaD}$ entre alunos, professores e tutores (Hack, 2011; Momo \& Behr, 2015).

A EaD está presente em diversas instituições de ensino no país, devido ao seu crescimento e expansão nos últimos anos, das tecnologias de informação e comunicação, e das políticas de democratização da oferta de educação no país, o que demonstra o caráter inclusivo e universal da EaD (Bicalho \& Medeiros, 2018; Cruz \& Molina, 2019).

Para prover o ensino nesta modalidade, um sistema EaD depende de uma rede de suporte em diversos níveis (administrativo, pedagógico, tecnológico, etc.), devendo contar com uma gestão eficiente, de modo a propiciar às instituições que atuam na modalidade o melhor uso de recursos e conhecimentos (Hack, 2011; Momo \& Behr, 2015).

Nesse sentido, a atuação e gestão de sistemas EaD também se relaciona com a Gestão do Conhecimento, por contemplar um modelo organizacional baseado no compartilhamento do conhecimento, por meio de ações e construções coletivas, e a união de esforços para a sua finalidade precípua (Alarcon \& Spanhol, 2015; Hack, 2011; Novello \& Laurino, 2012).

A EaD representa um modelo de educação sustentável, mas a aplicação da $\mathrm{GC}$ em seu contexto pode contribuir para estar em constante renovação, em conjunto com a utilização de metodologias inovadoras de ensino, do trabalho colaborativo e das tecnologias digitais (Bento et al., 2017; Bicalho \& Medeiros, 2018).

A GC se faz com pessoas. Por isso, a EaD tem por essência formar equipes multidisciplinares, com talentos de diferentes áreas que atuam de forma cooperativa e em rede, e que buscam novas formas para criar e expandir conhecimento e cumprir metas de trabalho (Alarcon \& Spanhol, 2015; Novello \& Laurino, 2012; Schuelter \& Coelho, 2010). 


\section{Práticas de Gestão do Conhecimento aplicadas no sistema de EaD de uma instituição federal de ensino no Sul Fluminense}

Dessa forma, a GC pode ser considerada uma ferramenta importante para organizações intensivas em conhecimento, como as que atuam na $\mathrm{EaD}$, com práticas que incentivem fluxos de conhecimento entre pessoas, equipes e organização (Alarcon \& Spanhol, 2015).

Com o crescimento da EaD e o aumento da competitividade no mercado, muitas instituições verificam a necessidade de melhoria de seus processos organizacionais a partir do uso das práticas de GC. Por esta razão, a GC pode trazer diferencial competitivo e contribuir para a geração e troca de informações e conhecimentos, a partir da interação entre os profissionais da EaD nestas instituições (Cruz \& Molina, 2019).

\section{METODOLOGIA}

A pesquisa possui abordagem qualitativa, de cunho interpretativo (Creswell, 2014). Utilizou-se a estratégia de estudo de caso (Yin, 2015), ao investigar o fenômeno dentro da realidade do universo pesquisado. Também apresenta abordagem quantitativa, ao contemplar dados que podem explicar fenômenos e características, ao aplicar alguma forma de análise e interpretação por técnicas estatísticas, para descrever e interpretar tais dados (Malhotra, 2001).

Para chegar ao objetivo final do estudo, a pesquisa apresentou natureza exploratória e descritiva (com vistas à compreensão da realidade e à descrição dos fatos e características da realidade estudada) (Gil, 2008).

Os sujeitos da pesquisa foram os integrantes do sistema de $\mathrm{EaD}$ da instituição pesquisada, que atuaram nas atividades do referido sistema entre os anos de 2017 e 2018 . Por se tratar de um número limitado de pessoas, estes compuseram a amostra na sua totalidade.

Para a coleta de dados, foi utilizado como instrumento um questionário semiestruturado, com perguntas fechadas e abertas, adaptado dos estudos de Batista (2012), Batista e Quandt (2015), Hellmann (2007) e Leuch (2006), aplicado em diversas organizações, para identificar as práticas de GC nestes entes.

Este questionário foi aplicado entre julho e setembro de 2019, e buscou diagnosticar as práticas de GC aplicadas no sistema de $\mathrm{EaD}$ da instituição, e verificar o grau de conhecimento e frequência de sua utilização. Para determinar se a prática era aplicada, considerou-se a sua utilização frequente acima de $50 \%$, ou se a soma entre pouca e muita frequência fosse igual ou superior a 50\% de utilização.

O questionário também buscava obter a percepção dos respondentes quanto a melhorias que poderiam ser vistas na $\mathrm{EaD}$ e na organização, a partir de uma possível implementação da $\mathrm{GC}$, bem como as razões e em quais aspectos estas melhorias aconteceriam. 


\section{Práticas de Gestão do Conhecimento aplicadas no sistema de EaD de uma instituição federal de ensino no Sul Fluminense}

Nesse sentido, todos os sujeitos também receberam uma lista das 42 práticas de GC para consulta (conforme Quadro 2), além de instruções para preencher o questionário.

O questionário foi elaborado com o auxílio da ferramenta Google Forms, pelo fato desta permitir a construção intuitiva das perguntas, o envio por e-mail aos destinatários, além do recolhimento, extração e organização dos dados via planilhas no Google Sheets.

Houve também a coleta de dados via observação participante (Gil, 2008; Creswell, 2014), com o registro de notas de campo acerca do ambiente organizacional da EaD, com o intuito de verificar como essas práticas de GC eram aplicadas e desenvolvidas.

Quanto à análise dos dados coletados pelos instrumentos utilizados, os dados qualitativos foram tratados, organizados, interpretados e apresentados em textos e quadros, com informações e relatos que evidenciam a realidade organizacional encontrada. Os dados quantitativos foram apurados por meio de técnicas de estatística descritiva, tais como análise de distribuição de frequência absoluta e relativa dos dados.

\section{RESULTADOS E DISCUSSÃO}

Nesta seção, estão apresentados os resultados da pesquisa, obtidos a partir da análise dos dados dos questionários e dos registros da observação, indicando as práticas de GC aplicadas e como elas se desenvolvem no sistema de EaD pesquisado.

Antes disso, uma breve contextualização histórica da instituição e do setor, o que pode ajudar a entender particularidades e obstáculos enfrentados no que tange à GC.

\subsection{CARACTERIZAÇÃO DA ORGANIZAÇÃO}

O universo da pesquisa é o sistema de educação a distância $(\mathrm{EaD})$ (composto pelo Núcleo de Educação a Distância e pelos polos presenciais de EaD) de uma instituição federal de ensino, localizada na região sul do estado do Rio de Janeiro, e que com a Lei n ${ }^{\circ} 11.892 / 2008$, passou a fazer parte dos institutos federais (Brasil, 2008; IFRJ, 2015).

A missão da instituição é promover educação profissional, científica e tecnológica, formando cidadãos que sejam agentes de transformação social. Para tanto, ela oferece cursos em diversos níveis de ensino (médio-técnico, graduação, pós-graduação, etc.) (IFRJ, 2015; IFRJ, 2018; IFRJ, 2019).

A educação a distância na instituição iniciou em 2008, quando os primeiros cursos a distância foram aprovados. Em 2009, foram inaugurados o Núcleo de Educação a Distância $(\mathrm{NEaD})$ e os primeiros polos de apoio presencial. Desde então, o sistema de $\mathrm{EaD}$ acompanha e organiza a oferta desses cursos (IFRJ, 2015; IFRJ, 2018; IFRJ, 2019). Atualmente, os polos REGMPE, Brasil-BR, V.5, N³, p. 192-212, Set./Dez.2020 www.revistas.editoraenterprising.net Página 202 


\section{Práticas de Gestão do Conhecimento aplicadas no sistema de EaD de uma instituição federal de ensino no Sul Fluminense}

presenciais estão distribuídos em seis municípios diferentes do estado, entre o Sul Fluminense e região metropolitana do Rio de Janeiro.

Como princípios norteadores, a $\mathrm{EaD}$ na instituição se pauta na aprendizagem colaborativa e na democratização do acesso à educação pública daqueles que apresentam dificuldades em cursar o ensino presencial (IFRJ, 2015).

As atividades realizadas pelo sistema de EaD, no geral, são: oferta e acompanhamento de cursos a distância; acompanhamento de alunos, tutores e professores; disponibilização de ambientes para alunos e tutores; e suporte ao ambiente virtual de aprendizagem para os usuários do sistema de $\mathrm{EaD}$.

Os profissionais que compõem a equipe multidisciplinar do sistema de $\mathrm{EaD}$ são: coordenador geral (líder do sistema de EaD); coordenadores de cursos, tutoria e polos presenciais; professores; tutores e equipes de apoio técnico e administrativo e pedagógico.

Nesse sentido, pelo fato da $\mathrm{EaD}$ ter por essência a formação de equipes multidisciplinares, com diferentes funções e habilidades, conhecimentos diversos podem ser criados e inovados, a partir das interações entre todos, onde é possível aproveitá-los em favor do coletivo (Schuelter \& Coelho, 2010).

No caso em tela, para que o sistema de $\mathrm{EaD}$ da instituição aproveite esses conhecimentos nas atividades da modalidade, é necessário atentar-se à gestão desses conhecimentos, uma vez que estes formam a base para o trabalho do sistema. Isso pode trazer diversas melhorias, com o uso de práticas e ferramentas voltadas à dinâmica do conhecimento internamente.

A alta rotatividade de profissionais e a dinâmica que envolve o trabalho na $\mathrm{EaD}$ faz com que conhecimentos essenciais não sejam retidos ou aproveitados nas atividades do sistema, de forma que acabam sendo perdidos, o que gera diversos problemas para o sistema de $\mathrm{EaD}$.

No geral, há uma boa interação entre os colaboradores. Isso pode facilitar a troca de experiências e o compartilhamento de conhecimentos entre todos, de modo que este conhecimento possa ser retido e aproveitado nas atividades do sistema de $\mathrm{EaD}$.

\subsection{PRÁTICAS DE GC APLICADAS NO SISTEMA DE EaD}

Para diagnosticar as práticas de GC aplicadas no universo pesquisado, foi aplicado um questionário semiestruturado aos sujeitos da pesquisa, com o intuito de verificar o grau de conhecimento e frequência de uso destas práticas de GC no cotidiano da EaD.

Ao final da coleta de dados via questionários, do total de 80 indivíduos que compuseram a amostra selecionada para o estudo em questão, 32 responderam ao questionário, o que permitiu alcançar uma taxa de retorno de $40 \%$.

REGMPE, Brasil-BR, V.5, No3, p. 192-212, Set./Dez.2020 www.revistas.editoraenterprising.net Página 203 


\section{Práticas de Gestão do Conhecimento aplicadas no sistema de EaD de uma instituição federal de ensino no Sul Fluminense}

Ao mesmo tempo em que os questionários eram aplicados, houve a coleta de dados via observação, para que pudesse ser feita uma análise conjunta de quais práticas de GC eram aplicadas e como elas se desenvolviam no universo de pesquisa.

No quadro abaixo (Quadro 3), são apresentados os resultados obtidos acerca do grau de conhecimento e frequência de uso das práticas de GC no sistema de EaD da instituição.

Quadro 3

Grau de conhecimento e frequência de uso das práticas de GC no sistema de EaD

\begin{tabular}{|c|c|c|c|c|}
\hline & \multicolumn{4}{|c|}{ Conhecimento e Frequência de Uso } \\
\hline Práticas de GC & $\begin{array}{c}\text { Desconheço } \\
\text { a prática }\end{array}$ & $\begin{array}{c}\text { Conheço, } \\
\text { mas não é } \\
\text { utilizada }\end{array}$ & \begin{tabular}{|c|} 
Utilizada \\
com pouca \\
frequência
\end{tabular} & $\begin{array}{c}\text { Utilizada } \\
\text { com } \\
\text { frequência }\end{array}$ \\
\hline $\begin{array}{l}\text { Fóruns presenciais e virtuais e listas de } \\
\text { discussão }\end{array}$ & $6,50 \%$ & $16,10 \%$ & $16,10 \%$ & $61,30 \%$ \\
\hline Comunidades de Prática & $31 \%$ & $34,60 \%$ & $17,20 \%$ & $17,20 \%$ \\
\hline Narrativas & $37,50 \%$ & $28,10 \%$ & $25 \%$ & $9,40 \%$ \\
\hline Mentoring & $37,50 \%$ & $46,90 \%$ & $9,40 \%$ & $6,30 \%$ \\
\hline Coaching & $28 \%$ & $59,40 \%$ & $6,30 \%$ & $6,30 \%$ \\
\hline Aprendizagem Organizacional & $25 \%$ & $31,20 \%$ & $21,90 \%$ & $21,90 \%$ \\
\hline Educação Corporativa & $12,50 \%$ & $28,10 \%$ & $43,80 \%$ & $15,60 \%$ \\
\hline Brainstorming & $21,90 \%$ & $43,70 \%$ & $21,90 \%$ & $12,50 \%$ \\
\hline Assistência de colegas & $34,40 \%$ & $25 \%$ & $3,10 \%$ & $37,50 \%$ \\
\hline Socialização & $3,10 \%$ & $21,80 \%$ & $31,30 \%$ & $43,80 \%$ \\
\hline Reuniões & $0 \%$ & $3,10 \%$ & $34,40 \%$ & $62,50 \%$ \\
\hline Revisão de aprendizagem & $40,70 \%$ & $15,60 \%$ & $15,60 \%$ & $28,10 \%$ \\
\hline Revisão pós-ação & $43,80 \%$ & $15,60 \%$ & $15,60 \%$ & $25 \%$ \\
\hline Espaço físico colaborativo & $15,60 \%$ & $15,60 \%$ & $31,30 \%$ & $37,50 \%$ \\
\hline Espaço virtual colaborativo & $12,50 \%$ & $9,40 \%$ & $21,80 \%$ & $56,30 \%$ \\
\hline Compartilhamento de vídeos & $28,10 \%$ & $25 \%$ & $9,40 \%$ & $37,50 \%$ \\
\hline Melhores práticas & $18,70 \%$ & $37,50 \%$ & $12,50 \%$ & $31,30 \%$ \\
\hline Benchmarking & $34,30 \%$ & $46,90 \%$ & $12,50 \%$ & $6,30 \%$ \\
\hline Normalização e padronização & $12,50 \%$ & $31,30 \%$ & $15,60 \%$ & $40,60 \%$ \\
\hline Mapeamento de processos & $12,50 \%$ & $50 \%$ & $21,90 \%$ & $15,60 \%$ \\
\hline Mapeamento do conhecimento & $21,90 \%$ & $40,70 \%$ & $18,70 \%$ & $18,70 \%$ \\
\hline Inteligência competitiva & $59,40 \%$ & $18,70 \%$ & $15,60 \%$ & $6,30 \%$ \\
\hline Sistema de gestão por competências & $40,60 \%$ & $31,30 \%$ & $12,50 \%$ & $15,60 \%$ \\
\hline $\begin{array}{l}\text { Memória organizacional/lições } \\
\text { aprendidas }\end{array}$ & $28,10 \%$ & $37,50 \%$ & $3,10 \%$ & $31,30 \%$ \\
\hline Banco de competências individuais & $25 \%$ & $40,60 \%$ & $25 \%$ & $9,40 \%$ \\
\hline Banco de competências organizacionais & $21,90 \%$ & $40,60 \%$ & $15,60 \%$ & $21,90 \%$ \\
\hline
\end{tabular}

REGMPE, Brasil-BR, V.5, No3, p. 192-212, Set./Dez.2020 www.revistas.editoraenterprising.net Página 204 
Práticas de Gestão do Conhecimento aplicadas no sistema de EaD de uma instituição federal de ensino no Sul Fluminense

\begin{tabular}{|c|c|c|c|c|}
\hline Taxonomia & $56,30 \%$ & $18,70 \%$ & $15,60 \%$ & $9,40 \%$ \\
\hline Bases de conhecimento & $37,50 \%$ & $31,30 \%$ & $12,50 \%$ & $18,70 \%$ \\
\hline Repositórios de conhecimento & $34,40 \%$ & $34,40 \%$ & $12,50 \%$ & $18,70 \%$ \\
\hline Gestão do capital intelectual & $59,40 \%$ & $28 \%$ & $6,30 \%$ & $6,30 \%$ \\
\hline Ferramentas de colaboração & $9,40 \%$ & $9,40 \%$ & $18,70 \%$ & $62,50 \%$ \\
\hline Voz sobre IP & $34,40 \%$ & $18,70 \%$ & $21,90 \%$ & $25 \%$ \\
\hline Redes sociais e E-mails & $3,20 \%$ & $3,20 \%$ & $12,90 \%$ & $80,70 \%$ \\
\hline Ferramentas de busca avançada & $18,70 \%$ & $6,30 \%$ & $34,40 \%$ & $40,60 \%$ \\
\hline Sistemas de workflow & $65,60 \%$ & $18,70 \%$ & $6,30 \%$ & $9,40 \%$ \\
\hline Gestão de conteúdo & $43,80 \%$ & $12,50 \%$ & $15,60 \%$ & $28,10 \%$ \\
\hline Gestão eletrônica de documentos (GED) & $28,10 \%$ & $21,90 \%$ & $34,40 \%$ & $15,60 \%$ \\
\hline ERP (Enterprise Resource Planning) & $53,10 \%$ & $31,20 \%$ & $6,30 \%$ & $9,40 \%$ \\
\hline DSS (Decision Support System) & $68,80 \%$ & $21,80 \%$ & $3,10 \%$ & $6,30 \%$ \\
\hline Data Warehouse e Data Mining & $78,20 \%$ & $18,70 \%$ & $0 \%$ & $3,10 \%$ \\
\hline BSC (Balanced ScoreCard) & $68,80 \%$ & $21,80 \%$ & $6,30 \%$ & $3,10 \%$ \\
\hline
\end{tabular}

Fonte: Dados da pesquisa (2019). Elaborado pelo autor.

Baseado nos critérios para determinar a aplicação das práticas de GC no sistema de EaD, observou-se um número baixo de práticas aplicadas. Do total de 42 práticas elencadas, apenas 10 são utilizadas pelos profissionais da $\mathrm{EaD}$, algumas com maior frequência e outras com frequência em casos pontuais. Tais práticas estão apresentadas no quadro abaixo (Quadro 4).

Quadro 4

Práticas de GC aplicadas no sistema de EaD pesquisado

\begin{tabular}{|c|c|c|c|c|}
\hline & \multicolumn{3}{|c|}{ Conhecimento e Frequência de Uso } \\
\hline Práticas de GC & $\begin{array}{c}\text { Desconheço } \\
\text { a prática }\end{array}$ & $\begin{array}{c}\text { Conheço } \\
\text { mas náo } \\
\text { é } \\
\text { utilizada }\end{array}$ & $\begin{array}{c}\text { Utilizada } \\
\text { com pouca } \\
\text { frequência }\end{array}$ & $\begin{array}{c}\text { Utilizada } \\
\text { com } \\
\text { frequência }\end{array}$ \\
\hline $\begin{array}{c}\text { Fóruns presenciais e virtuais e listas de } \\
\text { discussão }\end{array}$ & $6,50 \%$ & $16,10 \%$ & $16,10 \%$ & $61,30 \%$ \\
\hline Educação Corporativa & $12,50 \%$ & $28,10 \%$ & $43,80 \%$ & $15,60 \%$ \\
\hline Socialização & $3,10 \%$ & $21,80 \%$ & $31,30 \%$ & $43,80 \%$ \\
\hline Espaço físico colaborativo & $15,60 \%$ & $15,60 \%$ & $31,30 \%$ & $37,50 \%$ \\
\hline Espaço virtual colaborativo & $12,50 \%$ & $9,40 \%$ & $21,80 \%$ & $56,30 \%$ \\
\hline Reuniões & $0 \%$ & $3,10 \%$ & $34,40 \%$ & $62,50 \%$ \\
\hline Normalização e padronização & $12,50 \%$ & $31,30 \%$ & $15,60 \%$ & $40,60 \%$ \\
\hline Ferramentas de colaboração & $9,40 \%$ & $9,40 \%$ & $18,70 \%$ & $62,50 \%$ \\
\hline Gestão eletrônica de documentos (GED) & $28,10 \%$ & $21,90 \%$ & $34,40 \%$ & $15,60 \%$ \\
\hline Redes sociais e E-mails & $3,20 \%$ & $3,20 \%$ & $12,90 \%$ & $80,70 \%$ \\
\hline
\end{tabular}

REGMPE, Brasil-BR, V.5, N³, p. 192-212, Set./Dez.2020 www.revistas.editoraenterprising.net Página 205 


\section{Práticas de Gestão do Conhecimento aplicadas no sistema de EaD de uma instituição federal de ensino no Sul Fluminense}

Fonte: Dados da pesquisa (2019). Elaborado pelo autor.

Dentre as práticas aplicadas, observa-se que as práticas relacionadas a processos (GED e normalização/padronização) são menos frequentes, ao passo que as práticas relacionadas às pessoas e à tecnologia tem maior frequência de uso.

Os Fóruns presenciais/virtuais e listas de discussão são espaços para compartilhar informações, ideias e experiências, e permitem desenvolver competências e aperfeiçoar processos e atividades da organização (Batista, 2012).

$\mathrm{Na} \mathrm{EaD}$, é um recurso muito utilizado por todos os atores envolvidos na $\mathrm{EaD}$, além de promover o compartilhamento e o armazenamento do conhecimento entre equipes multidisciplinares, ao permitir criar memória organizacional (Alarcon \& Spanhol, 2015).

No sistema de $\mathrm{EaD}$, tal prática se faz presente na rotina dos colaboradores, em especial dos alunos, tutores e professores, com a disponibilização de informações e conteúdo, presencialmente ou virtualmente. Essa prática contribui para a geração e disseminação de conhecimentos na EaD da instituição.

A Educação Corporativa compreende a educação continuada de colaboradores para atualização, o que permite o autodesenvolvimento da instituição como um todo, e pode ser feita com treinamento interno, ensino a distância, etc. (Batista, 2012; Bento et al., 2017).

Nesse sentido, há iniciativas de capacitação trimestrais, por conta da rotatividade e da renovação dos colaboradores, e são voltadas para a ambientação destes quanto ao uso da plataforma virtual e ao desenvolvimento do trabalho na EaD.

A Socialização busca promover o encontro e o relacionamento entre os indivíduos, em eventos ou atividades, para troca de conhecimentos tácitos (Leuch, 2006).

Neste sentido, o sistema de EaD promove iniciativas pontuais, que visam estreitar o relacionamento e estimular a troca de conhecimentos entre os profissionais do $\mathrm{NEaD}$ e dos polos, como eventos de recepção aos novos colaboradores, oficinas, orientações, etc.

Os Espaços Físico e Virtual colaborativos representam o trabalho cooperativo entre pessoas e equipes, com a criação de novos produtos ou processos de trabalho, compartilhando ideias, experiências, informações e conhecimentos, de forma presencial ou remota (Alarcon \& Spanhol, 2015; Hellmann, 2007; Leuch, 2006).

No NEaD, há um espaço próprio para colaboração. Nos polos presenciais, é o próprio espaço do polo. Mas a colaboração é mais frequente via ambiente virtual, pela troca de conhecimentos entre os profissionais, e da interação de tutores e professores com os alunos. 


\section{Práticas de Gestão do Conhecimento aplicadas no sistema de EaD de uma instituição federal de ensino no Sul Fluminense}

As Reuniões contam com os membros das equipes multidisciplinares, e são realizadas de forma geral ou por equipes específicas, no $\mathrm{NEaD}$ e nos polos, com a finalidade de discutir sobre o trabalho, propor melhorias, etc.

A Normalização e Padronização consiste na definição e elaboração de normas, procedimentos e documentos unificados, além do estabelecimento de padrões para as rotinas e atividades, de modo a serem seguidos e utilizados no contexto organizacional (Leuch, 2006).

Esta prática, está sendo implementada apenas no $\mathrm{NEaD}$, de modo a se padronizar rotinas, tarefas e atividades na $\mathrm{EaD}$, e tem como destinatários todas as equipes multidisciplinares. Ainda não está presente nos polos.

As Ferramentas de Colaboração consistem em sistemas de informação que disponibilizam conhecimento e experiências entre colaboradores e setores organizacionais. Tais sistemas servem de repositório de informações e conhecimentos para a organização e seus membros (Batista, 2012).

No sistema de $\mathrm{EaD}$, sua utilização remete ao próprio ambiente virtual, que serve como portal de informações para colaboradores e alunos da modalidade. Nele, estão disponibilizadas informações relevantes em $\mathrm{EaD}$, além de ser um canal de comunicação para o processo de ensino e aprendizagem.

A Gestão Eletrônica de Documentos (GED) consiste em adotar aplicativos informatizados de controle de emissão, edição e acompanhamento do ciclo de vida de documentos, ao substituir o papel por documentos digitais, com o histórico informativo destes e da organização, permitindo construir memória organizacional (Batista, 2012; Leuch, 2006).

Essa prática está em fase inicial de implantação no sistema de EaD e a sua aplicação já é vista pelos colaboradores, com a utilização de um sistema de informações que permite a tramitação de documentos digitalizados, em substituição aos documentos em papel.

Já as Redes Sociais consistem na formação de grupos de pessoas com interesses comuns em determinadas áreas. Elas auxiliam na interação via Internet, com o uso de aplicativos. Permite encontrar pessoas, compartilhar conteúdo, facilitar a comunicação, etc. (Batista, 2012).

Os E-mails também colaboram com a disseminação de conhecimentos dentro de uma organização, bem como é um facilitador no processo de comunicação formal entre os colaboradores, principalmente em caráter oficial (Batista, 2012).

No sistema de $\mathrm{EaD}$, tanto as redes sociais quanto os e-mails são usados frequentemente para a comunicação entre os colaboradores, com o envio de informações, bem como para compartilhar conhecimentos e experiências na modalidade.

REGMPE, Brasil-BR, V.5, №3, p. 192-212, Set./Dez.2020 www.revistas.editoraenterprising.net Página 207 


\section{Práticas de Gestão do Conhecimento aplicadas no sistema de EaD de uma instituição federal de ensino no Sul Fluminense}

Tais práticas facilitam a interação entre pessoas e grupos, e são de suma importância para compartilhar conhecimentos e informações entre os colaboradores de toda a $\mathrm{EaD}$, uma vez que permitem a comunicação de maneira dinâmica.

Todas essas 10 práticas citadas pelos respondentes como aplicadas no sistema de EaD podem ser aprimoradas na sua utilização cotidiana, com vistas a um alcance maior. Além destas, outras práticas de GC foram mencionadas por eles e podem ser implementadas na EaD ao longo do tempo, como: Comunidades de Prática, Coaching, Brainstorming, Melhores Práticas, Memória Organizacional/Lições Aprendidas, Mapeamento de Processos e do Conhecimento.

Os colaboradores também responderam se a implementação efetiva das práticas de GC traria melhorias à $\mathrm{EaD}$ da instituição, e por quais razões e em quais aspectos. Eles acreditam que a implementação de práticas de GC mais apropriadas à EaD pode trazer diversas melhorias benefícios para a EaD e para a instituição.

As respostas obtidas focam em mudanças culturais e rompimento de paradigmas acerca da construção, retenção, preservação, atualização, transferência e aplicação do conhecimento aplicável à EaD nas atividades do sistema de $\mathrm{EaD}$ em diversos aspectos.

Tais aspectos relacionados às melhorias e benefícios que a GC poderia trazer para o sistema de EaD encontram consonância nos estudos de Alarcon e Spanhol (2015) e Cruz e Molina (2019), quando estes apontam que a GC traz efetividade às ações organizacionais, melhora o desempenho, aumenta a competitividade e introduz uma cultura voltada para o gerenciamento adequado e efetivo do conhecimento aplicável à modalidade.

$\mathrm{O}$ baixo número de práticas de $\mathrm{GC}$ aplicadas no sistema de $\mathrm{EaD}$ da instituição pode indicar que a GC não é plenamente realizada neste universo, pois não há um projeto formal de GC. Neste sentido, vislumbra-se campo e potencial de exploração para a aplicação de mais práticas de GC no sistema de $\mathrm{EaD}$, a partir da implementação e formalização de outras práticas, adequadas ao contexto da $\mathrm{EaD}$, e o aprimoramento das que já são aplicadas.

Ao considerar a relação entre a $\mathrm{GC}$ na $\mathrm{EaD}$ e os benefícios que a GC pode proporcionar em termos de qualidade de ensino e desempenho organizacional, a formalização de tais práticas de GC podem contribuir para uma melhor dinâmica do conhecimento, bem como gerar resultados satisfatórios para o sistema de $\mathrm{EaD}$ e para a instituição como um todo.

\section{CONSIDERAÇÕES FINAIS}

O objetivo deste estudo foi diagnosticar as práticas de GC aplicadas no sistema de EaD de uma instituição federal de ensino no Sul Fluminense. Os resultados permitiram identificar a 


\section{Práticas de Gestão do Conhecimento aplicadas no sistema de EaD de uma instituição federal de ensino no Sul Fluminense}

aplicação de poucas práticas de GC, a frequência de uso destas e como se desenvolvem neste universo. Conclui-se que a GC no sistema de EaD ainda é pouco explorada e outras práticas de GC podem ser aplicadas, com vistas a melhorar o desempenho e aumentar a competitividade.

Com base nos resultados obtidos, são propostas as seguintes recomendações para uma implementação efetiva da GC no sistema de $\mathrm{EaD}$ da instituição: elaborar um plano de implementação da GC, composto pelas etapas de diagnóstico, planejamento, desenvolvimento e efetiva implementação; e criar um programa de GC para a modalidade $\mathrm{EaD}$, com ações que estimulem a prática da GC no contexto educacional e organizacional, com o envolvimento dos colaboradores nestas ações.

As limitações do estudo se concentraram na coleta e análise dos dados. Apesar de se utilizar uma amostra intencional, nem todos os sujeitos convidados a responder o questionário o fizeram; e seus resultados não podem ser generalizados, por conta da delimitação ao universo pesquisado. Porém, a descrição do método de análise para o diagnóstico das práticas de GC pode ser usada em outros estudos relacionados à temática.

Para estudos futuros, sugere-se realizar pesquisas relacionadas à $\mathrm{GC}$ na $\mathrm{EaD}$ em outras instituições de ensino, para verificar como o conhecimento é gerido nestes locais, e comparar diferenças e semelhanças quanto às práticas de GC adotadas e como elas são desenvolvidas no contexto da $\mathrm{EaD}$.

Assim, seria possível identificar as práticas de GC mais adequadas a aplicar no segmento da $\mathrm{EaD}$ em geral, as melhores ferramentas e metodologias utilizadas para adequar e implementar a GC, a melhor maneira de estimular o ciclo do conhecimento, e também os benefícios obtidos após implementar e formalizar a GC nestas instituições.

\section{REFERÊNCIAS}

Alarcon, D. F., \& Spanhol, F. J. (2015). Gestão do conhecimento na educação a distância: práticas para o sucesso. São Paulo: Pimenta Cultural.

Batista, F. F. (2012). Modelo de gestão do conhecimento para a administração pública brasileira: como implementar a gestão do conhecimento para produzir resultados em benefício do cidadão. Brasília: Ipea.

Batista, F. F., \& Quandt, C. O. (2015). Gestão do conhecimento na administração pública: resultados da pesquisa Ipea 2014 - Práticas de Gestão do Conhecimento. Texto para discussão n. 2120. Brasília: Ipea. 


\section{Práticas de Gestão do Conhecimento aplicadas no sistema de EaD de uma instituição federal de ensino no Sul Fluminense}

Bento, J. C., Urpia, A. G. B. D. C., Bortolozzi, F., \& Massuda, E. M. (2017). Nível de implantação e alcance das práticas da gestão do conhecimento em base tecnológica e funcional de organização educacional. Revista Alcance, 24 (2), 243-257. Doi: https://doi.org/10.14210/alcance.v24n2.p243-257.

Bicalho, R. N. de M. \& Medeiros, J. de C. (2018). O modelo híbrido de educação como estratégia para o processo de institucionalização da EaD. Revista Eixo, 7(2), 5-14. Doi: https://doi.org/10.19123/eixo.v7i2.615.

Brasil (2008). Lei n ${ }^{o} 11.892$, de 29 de dezembro de 2008. Brasília: Câmara dos Deputados.

Brasil (2019). Instituto Nacional de Estudos e Pesquisas Educacionais Anísio Teixeira (INEP). Censo da Educação Superior 2018: notas estatísticas. Brasília: INEP.

Brito, L. M. P., \& Bolson, S. B. (2014). Gestão do Conhecimento: Estudo em uma instituição privada de ensino superior. RAUnP, 6(2), 77-87. ISSN 1984-4204 - Doi: http://dx.doi.org/10.21714/raunp.

Creswell, J. W. (2014). Investigação qualitativa e projeto de pesquisa: escolhendo entre cinco abordagens. 3. ed. Porto Alegre: Penso.

Cribb, A. Y. (2010). Uma abordagem pragmática de construção de estratégias de gestão do conhecimento em organizações. Revista Ibero-americana de Sistemas, Cibernética e Informática, $\quad 7(1), \quad 75-80 . \quad$ Recuperado de http://www.iiisci.org/Journal/CV\$/risci/pdfs/MJ270AL.pdf.

Cruz, D. G. da, \& Molina, L. G. (2019). Concepções e práticas de gestão do conhecimento aplicadas a educação a distância. Revista Brasileira de Educação em Ciência da Informação, 6, 3-16. Recuperado de https://portal.abecin.org.br/rebecin/article/view/137.

Davenport, T. H., \& Prusak, L. (2012). Conhecimento Empresarial: como as organizações gerenciam seu capital intelectual (18a ed). Rio de Janeiro: Elsevier.

Drucker, P. F. (1999). Desafios gerenciais para o século XXI. São Paulo: Pioneira.

Gil, A. C. (2008). Métodos e técnicas de Pesquisa Social (6a. ed). São Paulo: Atlas.

Hack, J. R. (2011). Introdução à educação a distância. Florianópolis: LLV/CCE/UFSC.

Hellmann, C. L. (2007). Retenção de conhecimento tecnológico nas organizações como fator propulsor para o processo de inovação: estudo de caso na Batávia S/A. Dissertação de Mestrado, Universidade Tecnológica Federal do Paraná, Ponta Grossa, Brasil.

REGMPE, Brasil-BR, V.5, N³, p. 192-212, Set./Dez.2020 www.revistas.editoraenterprising.net Página 210 


\section{Práticas de Gestão do Conhecimento aplicadas no sistema de EaD de uma instituição federal de ensino no Sul Fluminense}

IFRJ - Instituto Federal do Rio de Janeiro. (2015). Plano de desenvolvimento institucional PDI: 2014 - 2018. Rio de Janeiro: IFRJ. Recuperado de https://migra.ifrj.edu.br/sites/default/files/webfm/images/PDI\%202014-2018.pdf. . (2018). Plano estratégico IFRJ: 2017 - 2021. Rio de Janeiro: IFRJ. . (2019). Apresentação da Educação a Distância do IFRJ. Rio de Janeiro: IFRJ. Recuperado de https://portal.ifrj.edu.br/ead.

Jannuzzi, C. S. C., Falsarella, O. M., \& Sugahara, C. R. (2016). Gestão do conhecimento: um estudo de modelos e sua relação com a inovação nas organizações. Perspectivas em Ciência da Informação, 21(1), 97-118. Doi: https://doi.org/10.1590/1981-5344/2462.

Leuch, V. (2006). Práticas de gestão do conhecimento em indústrias de grande porte dos Campos Gerais. Dissertação de Mestrado, Universidade Tecnológica Federal do Paraná, Ponta Grossa, Brasil.

Malhotra, N. K. (2001). Pesquisa de marketing. 3. ed. Porto Alegre: Bookman.

Momo, F. S., \& Behr, A. (2016). Gestão da Educação a Distância (EaD): uma significação a partir das práticas de gestão da Universidade Federal do Rio Grande do Sul (UFRGS). Em Rede - Revista de Educação a Distância, 2(2), 93-113. Recuperado de https://www.aunirede.org.br/revista/index.php/emrede/article/view/52.

Neves, M. L. C., Varvakis, G. J., \& Fialho, F. A. P. (2018). Pessoas, processos e tecnologia na gestão do conhecimento: uma revisão da literatura. Revista de Ciências da Administração, 20(51), 152-167. Doi: $\quad$ https://doi.org/10.5007/2175$\underline{8077.2018 \mathrm{v} 20 \mathrm{n} 51 \mathrm{p} 152 .}$

Nonaka, I., \& Takeuchi, H. (2008). Gestão do Conhecimento. Porto Alegre: Bookman.

Novello, T. P., \& Laurino, D. P. (2012). Educação a Distância: seus cenários e autores. Revista Ibero-americana de Educação, $58 \quad$ (4), 1-15. $\quad$ Doi: https://dx.doi.org/10.35362/rie5841419.

Santos, V. C. B., \& Damian, I. P. M. \& Valentim, M. L. P. (2019). A Cultura Organizacional como fator crítico de sucesso à implantação da Gestão do Conhecimento em organizações. Informação \& Sociedade, 29(1), 51-66. Doi: http://dx.doi.org/10.22478/ufpb.1809-4783.2019v29n1.38590. 
Práticas de Gestão do Conhecimento aplicadas no sistema de EaD de uma instituição federal de ensino no Sul Fluminense

Schreiber, D. (2015). O estudo da influência simbólica do líder no processo de Gestão do Conhecimento. Revista Gestão \& Tecnologia, 15 (1), 200-229. Doi: https://doi.org/10.20397/2177-6652/2015.v15i1.626.

Schuelter, G., \& Coelho, C. de S. R. (2010). A Gestão do Conhecimento nos sistemas de educação a distância: uma proposta inovadora para melhorar processos de produção. Travessias, $\quad$ 4(2). Recuperado de revista.unioeste.br/index.php/travessias/article/view/4158.

Silva, T., \& Burger, F. (2017). Aprendizagem organizacional e inovação: contribuições da Gestão do Conhecimento para propulsionar um ambiente corporativo focado em aprendizagem e inovação. Navus - Revista de Gestão e Tecnologia, 8 (1), 07-19. Doi: https://doi.org/10.22279/navus.2018.v8n1.p07-19.569.

Sveiby, K. E. (1998). A nova riqueza das organizações: gerenciando e avaliando patrimônio de conhecimento. Rio de Janeiro: Campus.

Yin, Robert K. (2015). Estudo de caso: planejamento e métodos. Porto Alegre: Bookman. 